\title{
Construction of Microparticles Based on Resorbable Polymers Bioplastotan Using Spray Drying Method
}

\author{
Anna M. Shershneva** and Ekaterina I. Shishatskayaa,b \\ ${ }^{a}$ Siberian Federal University \\ 79 Svobodny, Krasnoyarsk, 660041, Russia \\ ${ }^{b}$ Institute of Biophysics SB RAS \\ 50/50 Akademgorodok, Krasnoyarsk, 660036, Russia
}

Received 10.05.2014, received in revised form 28.05.2014, accepted 01.06.2014

The possibility of using the spray drying method for the construction of poly-3-hydroxybutyrate (P3HB) based microparticles was studied. The dependence of characteristics of microparticles (yield, average diameter, zeta-potential) from processing parameters (temperature at the inlet of the system, the feed rate of polymer solution and concentration of the polymer solution) was found. It is shown that zeta potential of microparticles was influenced by concentration of the polymer solution, and the average diameter was determined by temperature of the inlet. Also, conditions of obtaining P3HB microparticles were optimized to minimize polymer loss (approximately $10 \%$ ).

Keywords: drug delivery systems, polyhydroxyalkanoates, spray drying, microparticles, D-optimal design.

(C) Siberian Federal University. All rights reserved

* Corresponding author E-mail address: anna.kuzmina88@gmail.com 


\title{
Конструирование микрочастиц
}

\section{на основе резорбируемых полимеров Биопластотан с применением метода распылительной сушки}

\author{
А.М. Шершнева ${ }^{a}$, Е.И. Шишацкая ${ }^{\text {a, }}$ \\ ${ }^{a}$ Сибирский федеральный университет \\ Россия, 660041, Красноярск, пр. Свободньий, 79 \\ ${ }^{6}$ Институт биофизики СО РАН \\ Россия, 660036, Красноярск, Академгородок 50/50
}

Исследована возможность применения метода распьлительного высушивания для конструирования микрочастии на основе поли-3-гидроксибутирата (П(ЗГБ)). Установлена зависимость характеристик микрочастии (выход, средний диаметр, дзета-потенциал) от параметров процесса получения (температура на входе в систему, скорость подачи полимерного раствора и концентрация раствора полимера). Показано, что на величину дзетапотенциала микрочастиц достоверное влияние оказывала концентрация раствора полимера, а на средний диаметр - температура на входе в систему. Также в работе оптимизированы условия получения П(ЗГБ) микрочастии с минимальной потерей продукта (до $10 \%$ \%).

Ключевые слова: системы доставки лекарственных средств, полигидроксиалканоаты, распьлительное высушивание, микрочастицы, D-оптимальный дизайн.

\section{Введение}

Современное развитие науки приводит к широкому внедрению в медицине высокомолекулярных соединений, включая полиэфиры, синтезируемые живыми системами. Наиболее приоритетными полимерами в последнее десятилетие наряду с полилактидами и полигликолидами считаются полигидроксиалканоаты (ПГА) - полиэфиры алкановых кислот микробиологического происхождения. Этот класс биополимеров имеет широкие перспективы использования в качестве биорезорбируемого материала для создания систем контролируемой доставки лекарств. С целью использования ПГА для конструирования таких систем коллективом Института биофизики СО РАН и Сибирского федерального университета были всесторонне исследованы ме- тоды микронизации полимерных систем на основе ПГА с помощью высокоскоростных гомогенизаторов и ультразвуковой обработки эмульсий, что позволило получить семейство микрочастиц диаметром от 0,3 до 100 мкм (Goreva et al., 2012). Кроме того, в работах коллектива показана возможность нагружения микрочастиц антибактериальными и цитостатическими препаратами с длительной кинетикой оттока препаратов in vitro (до 30 сут) (Murueva et al., 2013). Доказана биологическая безопасность и лекарственная эффективность ПГА микрочастиц, несущих цитостатический препарат, в культуре опухолевых клеток и на животных с модельной карциномой Эрлиха (Шишацкая и др., 2012; Murueva et al., 2013).

Помимо широко применяемого эмульсионного метода, конструирование микро- 
частиц возможно другими различными способами: полимеризацией мономеров, ионным гелеобразованием или коацервацией, технологией сверхкритических жидкостей, методом атомизации, высушиванием растворов и т.д.

Среди перечисленных методов получения микрочастиц одним из перспективных является распылительное высушивание жидких и пастообразных материалов (spray drying) (Daugherty et al., 2006; Vehring, 2008; Ramezani et al., 2013). В основе данного метода лежит распыление материала в системе, которое производится форсунками (механическими и пневматическими) или центробежными дисками. Высушиваемый продукт с помощью форсунок диспергируется в сушильную камеру (рис. 1), в которой он контактирует с сушильным агентом (горячим воздухом или инертным газом). Методом распыления достигается значительное увеличение поверхности испарения. При этом происходит интенсивный массо- и теплообмен между высушиваемым продуктом и сушильным агентом. Диспергированные микрочастицы продукта теряют влагу за довольно небольшой промежуток времени. Высыхая, частицы под действием силы тяжести опускаются на дно сушильной камеры.

Метод микронизации полимерных систем с применением распылительного высушивания по сравнению с другими методами имеет ряд преимуществ:

- небольшая продолжительность процесса получения (сушка проходит практически мгновенно);

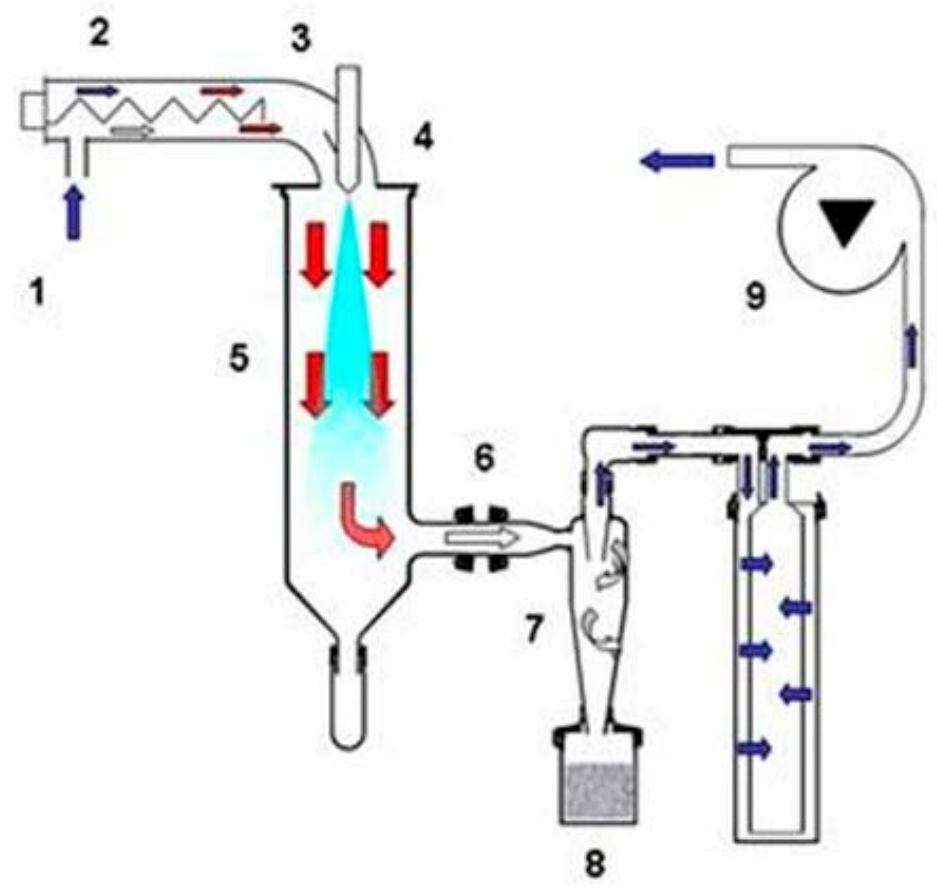

Рис. 1. Схематическое изображение получения микрочастиц на установке Mini Spray Dryer B-290 Advanced («BUCHI Laboratory Equipment»), где: 1 - подача сжатого воздуха или газа (аргон, азот); 2 - нагрев системы; 3 - датчик температуры на входе воздуха/газа в сушильную камеру; 4 - сопло распылителя; 5 - сушильная камера стабилизации входящих частиц; 6 - датчик температуры на выходе воздуха/газа из сушильной камеры; 7 - средний циклон: отделение продукта; 8 - малый циклон: для готового продукта; 9 - аспиратор 
- возможность регулирования показателей качества высушенного продукта путём изменения параметров режима сушки (объёмный вес сухого порошка, размер частиц, остаточная влажность и др.);

- большой диапазон возможных температур в зоне сушки: от 50 до $220{ }^{\circ} \mathrm{C}$;

- распылительное высушивание позволяет легко получить сухой продукт, состоящий из нескольких компонентов. Для этого их смешивают в жидком состоянии перед распылением в сушильной камере или производят их одновременное распыление;

- частицы, полученные в процессе распылительного высушивания различных образцов, обладают стабильностью даже при комнатной температуре (Anchordoquy et al., 2000).

Недостатком данного метода считался довольно низкий выход микрочастиц, который составлял порядка 20-50 \% от исходной массы вещества (Labrude et al., 1989; Johnson, 1997). Однако установлено, что данная величина может быть увеличена до 70-90 \% за счет внедрения высокопроизводительных циклонов для сбора высушенных микрочастиц и тщательного подбора рабочих параметров, которые играют ключевую роль в получении высококачественного продукта (Brandenberger, 2003; Shoyele et al., 2006).

В настоящее время в ряде работ изучено влияние параметров процесса получения методом распылительного высушивания на характеристики микрочастиц на основе различных материалов: сахаров дигидрата трегалозы и D(-)маннита (Lebrun et al., 2012); иммуноглобулина (IgG) человека (Mw 15 кДа), стабилизированного дигидратом трегалозы и D(-)маннитом (Ramezani et al., 2013); сополимера молочной и гликолевой кислот (ПМГК)
(Jensen et al., 2010); ПМГК с содержанием препаратов (Bege et al., 2013); гибридов ПМГК с соевым лецитином (Wang et al., 2012); микрофибриллированной целлюлозы (Kolakovic et al., 2012); низкомолекулярного хитозана (Mohajel et al., 2012). Однако при анализе coвременной литературы не найдено работ по изучению возможности применения метода распылительной сушки для конструирования микрочастиц на основе ПГА.

Это определило цель настоящей работы - конструирование микрочастиц на основе ПГА методом распылительного высушивания и исследование их характеристик (средний диаметр, электрокинетический потенциал).

\section{Материалы и методы}

Для получения микрочастиц использованы высокоочищенные образцы поли-3гидроксибутирата [П(ЗГБ)], синтезированного по разработанной технологии (Волова и др., 2001). Зарегистрированная марка материала и изделий - «Биопластотан» (Торговая марка «Биопластотан $\left.\left.{ }^{\mathrm{TM}}\right), 2006\right)$. Для отработки процесса получения микрочастиц методом распылительного высушивания с применением набора деполимеризующих реагентов были получены образцы П(ЗГБ) с молекулярной массой 6 кДа.

Микрочастицы на основе П(ЗГБ) получены на установке распылительной сушки Mini Spray Dryer B-290 («BUCHI Laboratory Equipment», Швейцария), оснащенной соплом распылителя (отверстие диаметром 0,7 мм), через которое подавался инертный газ (аргон) и с током газа под действием центробежных сил сухие частицы осаждались в высокопроизводительные циклоны.

Исследовано влияние параметров процесса получения микрочастиц на данной установке из растворов П(ЗГБ) в хлороформе разной концентрации $(0,5 ; 1,0$ и $1,5 \%)$. В ка- 
честве параметров получения, влияющих на характеристики полимерных микрочастиц, были выбраны: температура на входе в систему $\left(75,85\right.$ и $\left.95^{\circ} \mathrm{C}\right)$ и скорость подачи полимерного раствора (1,5; 3,2 и 5,0 мл/мин). Во всех исследуемых случаях величина аспиратора (ток газа) имела максимальный расход газа и составляла $35 \mathrm{~m}^{3} / ч$.

На анализаторе частиц Zetasizer Nano ZS (Malvern, Великобритания) с использованием метода динамического светорассеивания измерены характеристики полученных микрочастиц: средний диаметр, индекс полидисперсности (PdI), электрокинетический по-

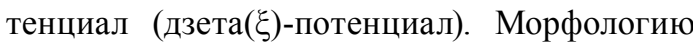
микрочастиц изучали с применением растрового микроскопа ТM-3000 (Hitachi, Япония).

Для оптимизации процесса получения П(ЗГБ) микрочастиц данным методом был использован D-оптимальный дизайн с программным обеспечением MatLab 7,0. Исследуемыми переменными в модели были характеристики микрочастиц: выход, средний диаметр и -потенциал. В качестве модели статистического анализа было выбрано уравнение:

$$
\begin{gathered}
\mathrm{Y}=\mathrm{a}_{1}+\mathrm{a}_{2} * \mathrm{X}_{1}+\mathrm{a}_{3} * \mathrm{X}_{2}+\mathrm{a}_{4} * \mathrm{X}_{3}+\mathrm{a}_{5} * \mathrm{X}_{1} * \mathrm{X}_{2}+ \\
+\mathrm{a}_{6} * \mathrm{X}_{1} * \mathrm{X}_{3}+\mathrm{a}_{7} * \mathrm{X}_{2} * \mathrm{X}_{3}+\mathrm{a}_{8} *\left(\mathrm{X}_{1}\right)^{2}+ \\
+\mathrm{a}_{9} *\left(\mathrm{X}_{2}\right)^{2}+\mathrm{a}_{10} *\left(\mathrm{X}_{3}\right)^{2}
\end{gathered}
$$

где $\mathrm{X}_{1}$ - исходная концентрация раствора полимера, $\mathrm{X}_{2}$ - температура на входе в систему, $\mathrm{X}_{3}$ - скорость подачи полимерного раствора.

Коэффициенты модели рассчитаны методом наименьших квадратов.

Статистическую обработку результатов проводили с использованием стандартного пакета программ Microsoft Excel, STATISTICA 8. Рассчитывали средние значения и ошибки среднего, достоверность различий оценивали с помощью t-критерия Стьюдента.

\section{Результаты и обсуждение}

На первом этапе отрабатывали получение микрочастиц из 0,5\%-ного раствора полимера при различных параметрах процесса. Выход микрочастиц варьировал в зависимости от скорости подачи полимерного раствора и температуры от 10 до 63 \% (табл. 1).

Все микрочастицы в исследуемых образцах имели правильную сферическую форму, но были гетерогенны по размеру (рис. 2). Во всех образцах зафиксированы крупные дефектные частицы (рис. 2, отмечено стрелкой), их количество составляло 1 \% от всего количества микрочастиц. Этот дефект микрочастиц, скорее всего, связан с образованием достаточно крупных полимерных капель, которые под действием высокого давления, созданного в системе, и высоких температур лопались, проходя через сушильную камеру. Подобные результаты наличия разорванных микрочастиц, полученных данным методом, были отмечены в работе Мохаджела с соавторами (Mohajel et al., 2012), в которой авторы исследовали влияние параметров распылительной сушки на характеристики микрочастиц из низкомолекулярного хитозана. Микрочастицы на основе П(ЗГБ), полученные на данной установке, полые внутри и могут содержать более мелкие микрочастицы в своей внутренней полости.

Размер микрочастиц, полученных из 0,5\%-ного раствора П(ЗГБ), варьировал от

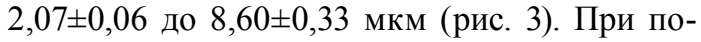
вышении скорости подачи раствора до 3,2 мл/мин при $85{ }^{\circ} \mathrm{C}$ и до 5 мл/мин при 75 и $95^{\circ} \mathrm{C}$ отмечено формирование более крупных микрочастиц.

Помимо размера, следующей важной характеристикой микрочастиц является дзета(ร)-потенциал - параметр, определяющий электрокинетическое взаимодействие между частицами, приближение к нулевому 
Таблица 1. Выход и дзета-потенциал микрочастиц, полученных из растворов П(ЗГБ) концентрацией 0,5 ; 1,0 и 1,5 \% при варьировании параметров процесса получения

\begin{tabular}{|c|c|c|c|c|c|c|c|}
\hline \multicolumn{2}{|c|}{ Параметры процесса } & \multicolumn{2}{|c|}{$\begin{array}{c}\text { Выход микрочастиц от } \\
\text { исходной массы полимера, \% }\end{array}$} & \multicolumn{3}{|c|}{ Дзета-потенциал, мВ } \\
\hline $\begin{array}{c}\text { Температура } \\
\text { на входе, }{ }^{\circ} \mathrm{C}\end{array}$ & $\begin{array}{c}\text { Скорость подачи } \\
\text { полимерного } \\
\text { раствора, мл/мин }\end{array}$ & 0,5 & 1,0 & 1,5 & 0,5 & 1,0 & 1,5 \\
\hline \multirow{3}{*}{75} & 1,5 & 10,0 & 33,2 & 49,0 & $-72,8$ & $-95,7$ & $-115,0$ \\
\cline { 2 - 9 } & 3,2 & 30,0 & 86,7 & 38,2 & $-83,7$ & $-94,5$ & $-105,0$ \\
\cline { 2 - 9 } & 5,0 & 37,5 & 84,7 & 83,0 & $-77,6$ & $-93,2$ & $-107,0$ \\
\hline \multirow{3}{*}{85} & 1,5 & 5,0 & 78,2 & 30,6 & $-69,5$ & $-87,1$ & $-101,0$ \\
\cline { 2 - 8 } & 3,2 & 35,0 & 90,5 & 47,3 & $-77,0$ & $-92,4$ & $-99,8$ \\
\hline \multirow{2}{*}{95} & 5,0 & 42,5 & 39,5 & 46,3 & $-66,6$ & $-89,0$ & $-103,0$ \\
\cline { 2 - 8 } & 1,5 & 60,0 & 75,7 & 84,0 & $-68,7$ & $-81,6$ & $-103,0$ \\
\cline { 2 - 8 } & 3,2 & 63,5 & 71,0 & 76,3 & $-81,6$ & $-77,4$ & $-102,0$ \\
\hline
\end{tabular}
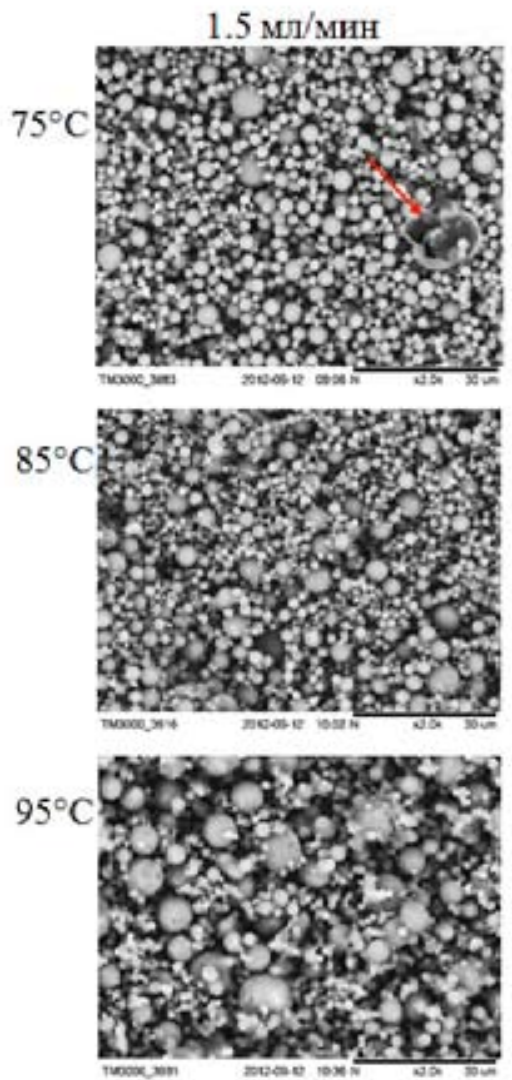
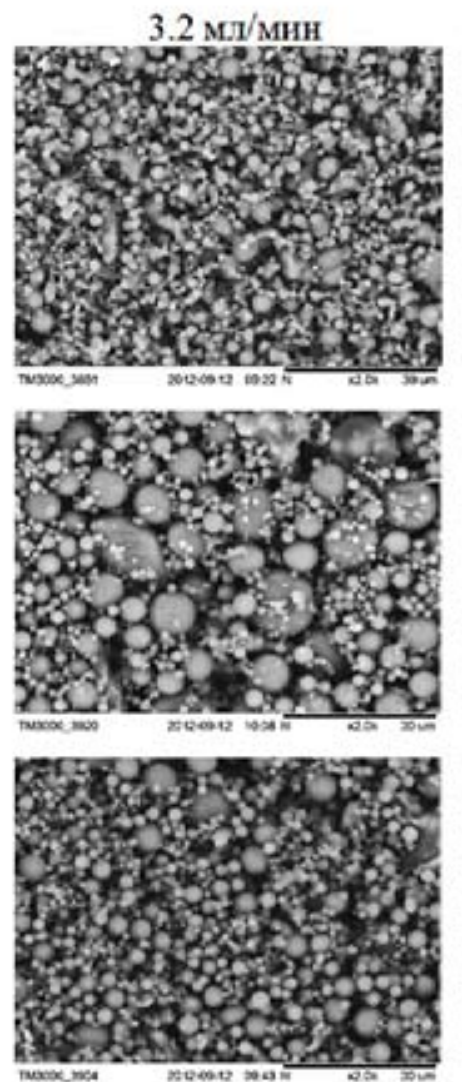
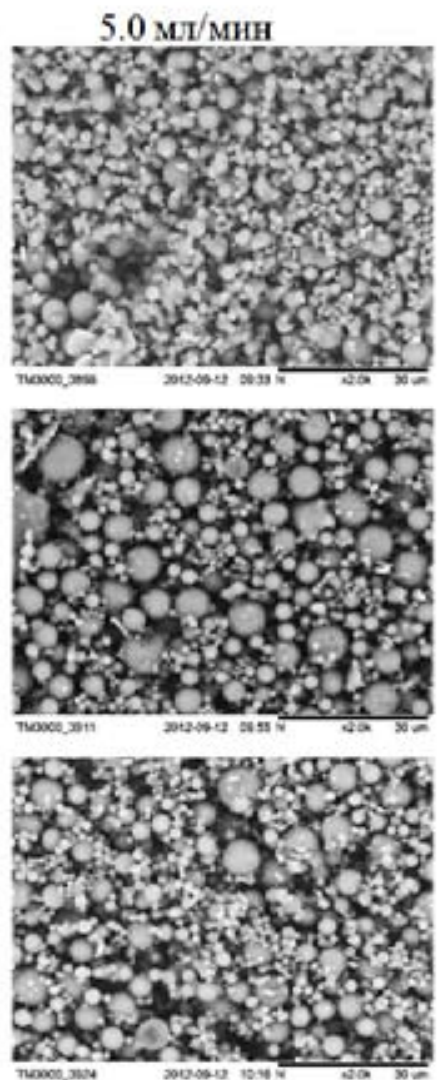

Рис. 2. РЭМ-снимки микрочастиц, полученных методом распылительной сушки из 0,5\%-ного раствора П(ЗГБ) при варьировании параметров: температура на входе в систему $\left({ }^{\circ} \mathrm{C}\right)$ и скорость подачи раствора (мл/мин). Маркер 30 мкм. Стрелкой показаны дефектные частицы 

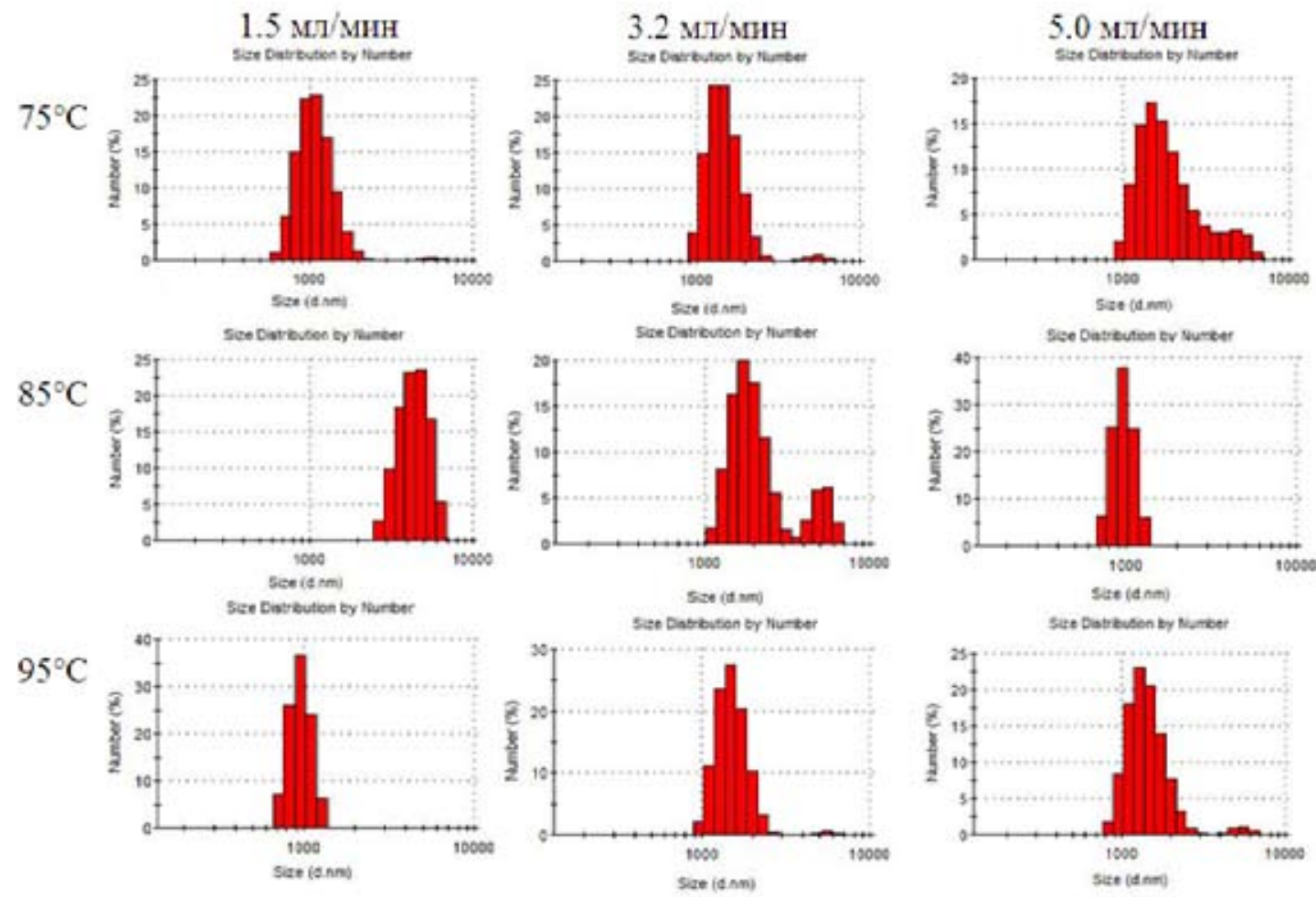

Рис. 3. Размерное распределение микрочастиц, полученных из 0,5\%-ного раствора П(ЗГБ) методом распылительной сушки при варьировании параметров: температура на входе в систему $\left({ }^{\circ} \mathrm{C}\right)$ и скорость подачи раствора (мл/мин)

значению которого позволяет частицам сближаться друг с другом и флоккулировать. По литературным данным, абсолютные значения $\xi$-потенциала свыше $30 \mathrm{mB}$ обеспечивают удовлетворительную, а свыше 60 мВ - высокую физическую стабильность коллоидных систем (Müller, 1996). У микрочастиц, полученных из 0,5\%-ного раствора П(ЗГБ),

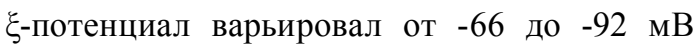
(табл. 1), что подтверждает физическую стабильность образцов.

Использование более плотного полимерного раствора П(ЗГБ) (1,0 \%) в отдельных случаях положительно влияло на выход микрочастиц, который мог составлять до 85-90 \% (табл. 1). Морфология микрочастиц и их размерное распределение при этом существенно не изменились (рис. 4,5 ). В целом, отмечено увеличение среднего диаметра, который при $75^{\circ} \mathrm{C}$ и скорости подачи раствора 1,5 мл/мин составлял $2,07 \pm 0,06$ и $6,51 \pm 0,47$ мкм для 0,5 и $1 \%$-ного растворов полимера соответственно (рис. 5). При этом имело место незначительное снижение электрокинетического потенциала на 10-15 мВ (табл. 1).

На следующем этапе было рассмотрено влияние параметров процесса получения микрочастиц при уплотнении раствора П(ЗГБ) до 1,5 \% (рис. 6). Микрочастицы также имели правильную сферическую форму и были гетерогенны по размеру. Это свидетельствует о том, что выбранные параметры получения не оказывают существенного влияния на форму полученных микрочастиц.

Размер микрочастиц варьировал от 3,5 до 6 мкм (рис. 7). При сравнении среднего диаметра микрочастиц, полученных из 1,0 и 1,5\%-ного растворов полимеров, видно, что 

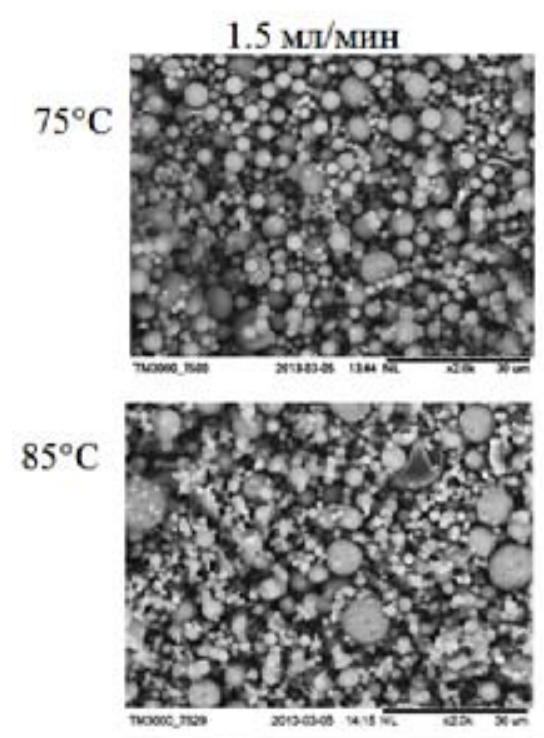

$95^{\circ} \mathrm{C}$

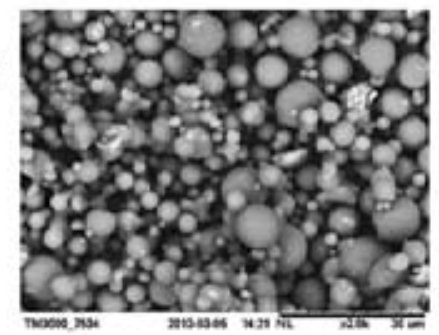

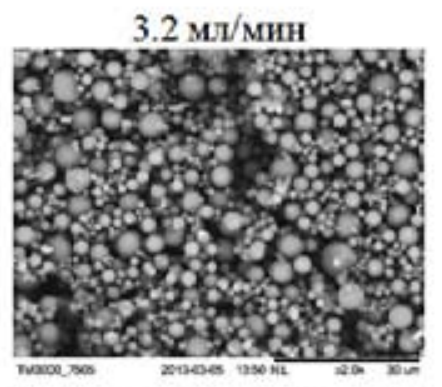
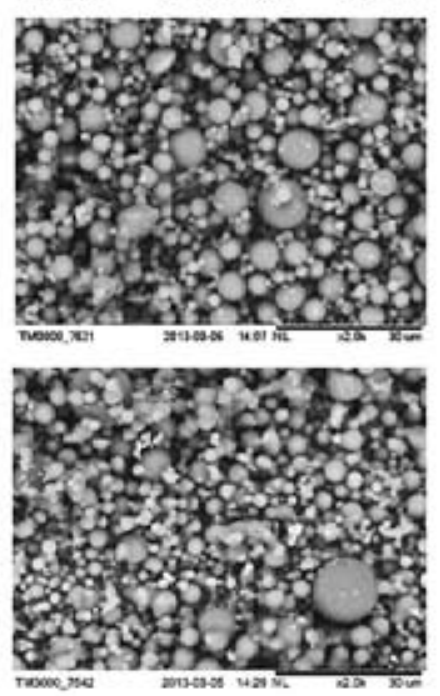

$5.0 \mathrm{MJ} / \mathrm{MHH}$
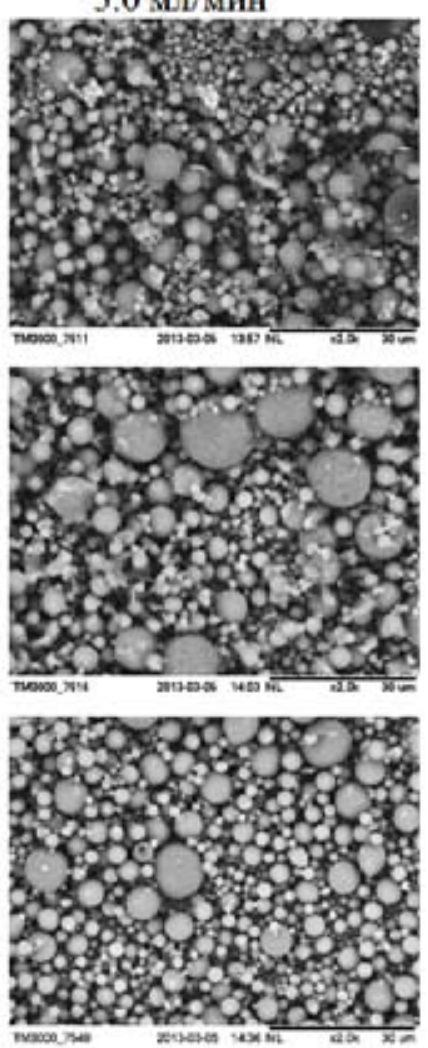

Рис. 4. РЭМ-снимки микрочастиц, полученных методом распылительной сушки из 1,0\%-ного раствора П(ЗГБ) при варьировании параметров: температура на входе в систему $\left({ }^{\circ} \mathrm{C}\right)$ и скорость подачи раствора (мл/мин). Маркер 30 мкм

при увеличении концентрации раствора до 1,5 \% в целом происходит снижение размера микрочастиц (рис. 5, рис. 7). Так, средний диаметр микрочастиц из 1,5\%-ного раствора составлял 4,5 мкм, в то время как из $1,0 \%-$ 5,8 мкм.

Для микрочастиц, полученных из 1,5\%ного раствора полимера, характерны абсолютные значения $\xi$-потенциала свыше $100 \mathrm{MB}$ (табл. 1). При этом минимальные значения

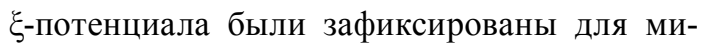
крочастиц, полученных при более низких температурах $\left(75^{\circ} \mathrm{C}\right)$ и составляли $-110 \mathrm{MB}$.

Следует отметить, что $\xi$-потенциал ПГА микрочастиц, полученных эмульсионным методом, варьирует в пределах -20 мB (Murueva et al., 2013). Однако величина

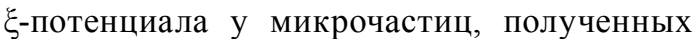
методом распылительного высушивания, варьировала в достаточно низком диапазоне от -70 до -110 мВ. Это свидетельствует о факте необратимой адсорбции на поверхности микрочастиц поверхностно-активных веществ, используемых в эмульсионном методе и отсутствующих в методе распылительного высушивания.

Модель D-оптимального дизайна получения П(ЗГБ) микрочастиц представлена в табл. 2 и 3, коэффициенты модели - в табл. 4. Результаты, представленные в столбцах «hypothesis» табл. 4, являются проверкой гипотезы (достоверности значений каждого параметра относительно 0). Если разброс значений содержал 0 либо имел положительный 


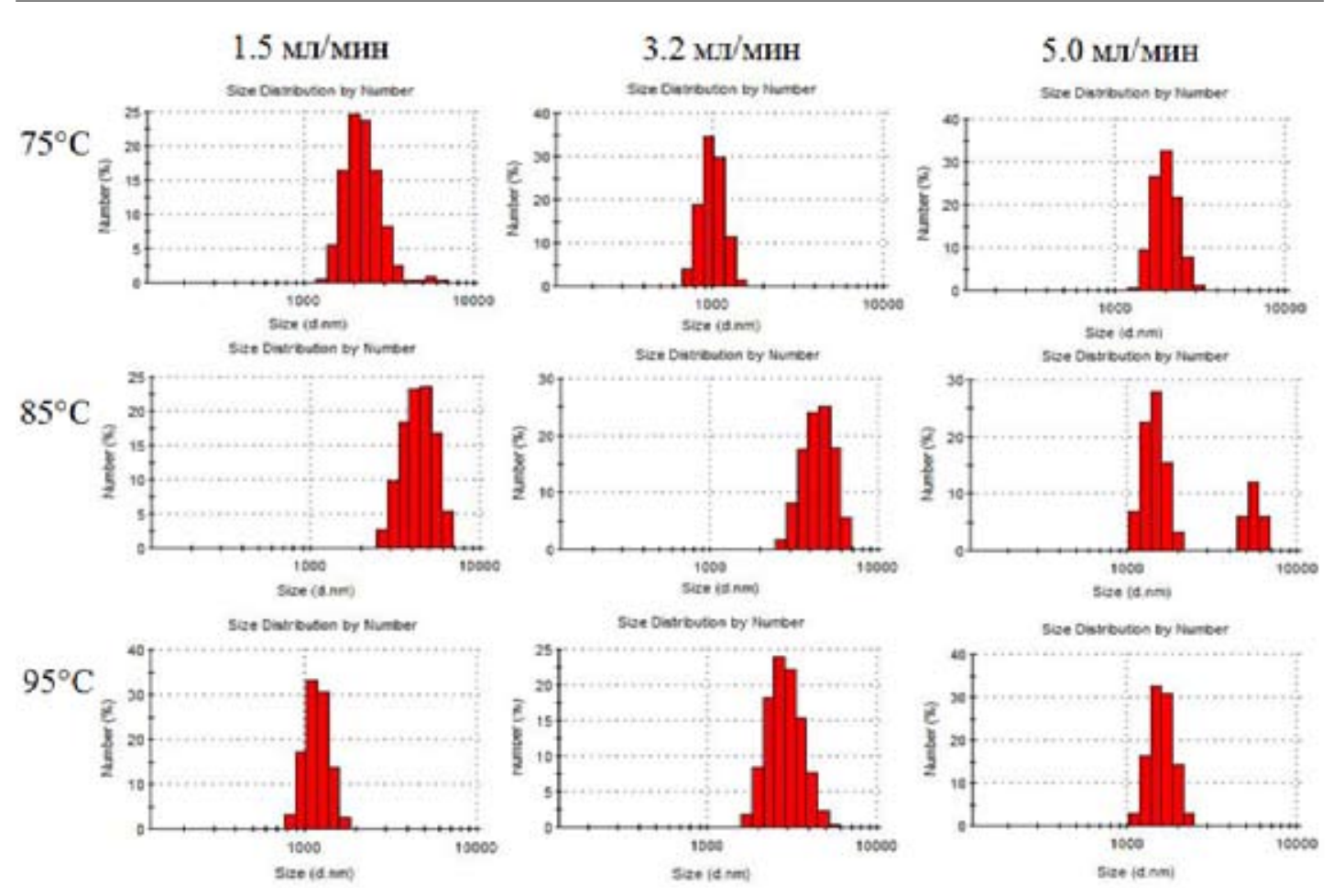

Рис. 5. Размерное распределение полимерных частиц, полученных из 1,0\%-ного раствора П(ЗГБ) методом распылительной сушки при варьировании параметров: температура на входе в систему ( $\left.{ }^{\circ} \mathrm{C}\right)$ и скорость подачи раствора (мл/мин)

Таблица 2. Список независимых переменных, используемых в статистической модели

\begin{tabular}{|c|c|c|c|c|c|}
\hline \multicolumn{7}{|c|}{ Параметры эксперимента } & \multirow{2}{*}{ Единица } \\
измерения \\
\hline Вход & High (+1) & Medium (0) & $\begin{array}{c}\text { Low } \\
(-1)\end{array}$ & $\%$ \\
\hline X2 & Концентрация & 1,5 & 1,0 & 0,5 & $\%$ \\
\hline X3 & Температура & 95 & 85 & 75 & ${ }^{\circ} \mathrm{C}$ \\
\hline
\end{tabular}

эффект, этот параметр считался незначительным. Если же эффект был отрицательным, то данный параметр имел сильное воздействие и был учтен.

Из полученных коэффициентов для уравнения (табл. 4) видно, что скорость подачи раствора (коэффициент $\mathrm{a}_{4}$ ) имела положительный эффект на все выбранные для исследования характеристики микрочастиц (выход, средний диаметр, -потенциал). А температура на входе в систему при этом имела практически во всех случаях самое мощное влияние, как видно по коэффициентам $\mathrm{a}_{3}$,

Показано, что единственнымпараметром, достоверно влияющим на размер микрочастиц $\left(\mathrm{У}_{2}\right)$, была температура на входе в систему (табл. 4). Относительно влияния остальных параметров процесса получения эффект был незначительным. Также по результатам табл. 4 видно, что наибольшее воздействие на $\xi$-потенциал микрочастиц $\left(\mathrm{V}_{3}\right)$ имела концентрация используемого раствора полимера. 

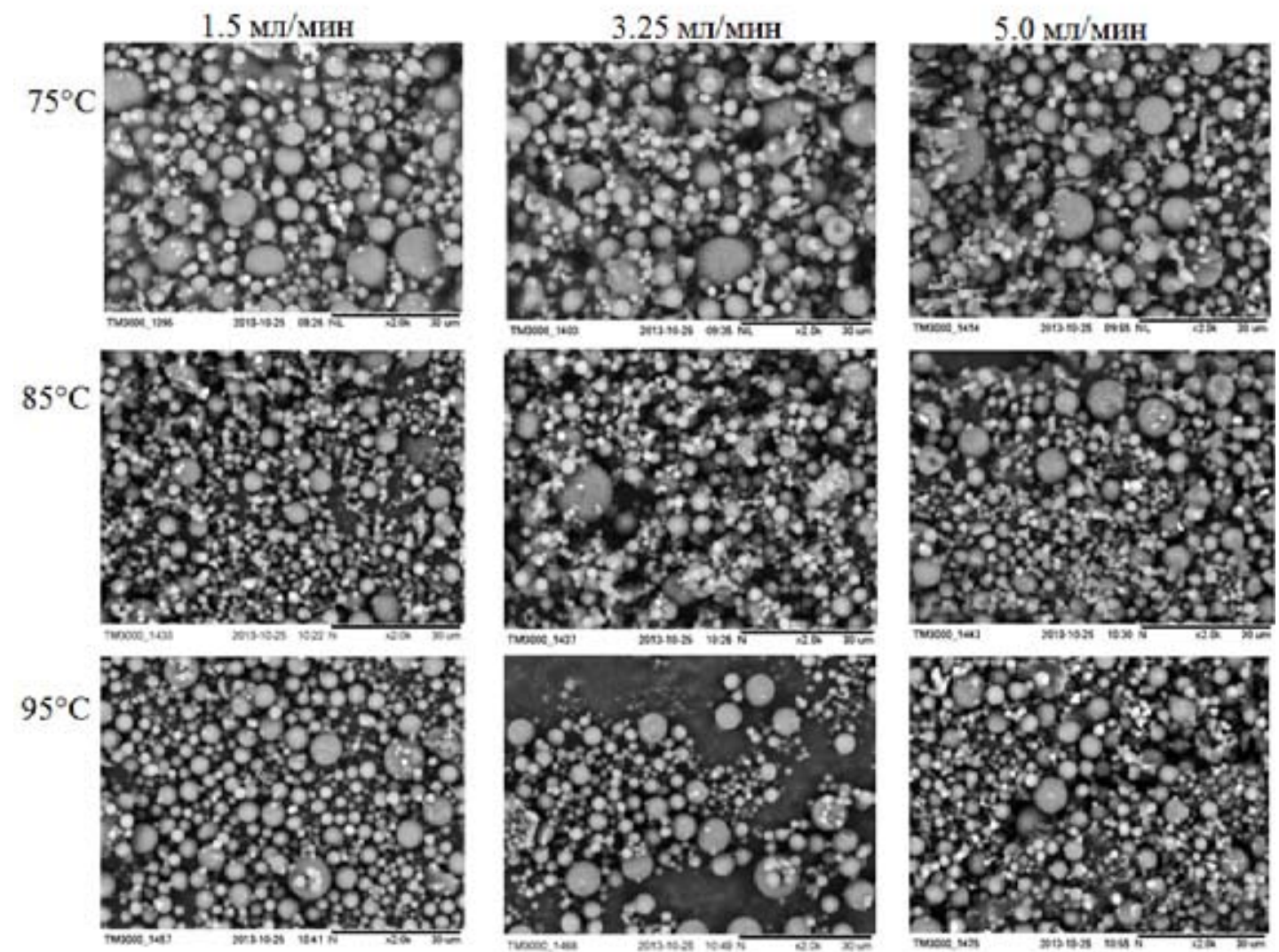

Рис. 6. РЭМ-снимки микрочастиц, полученных методом распылительной сушки из 1,5\%-ного раствора П(ЗГБ) при варьировании параметров: температура на входе в систему $\left({ }^{\circ} \mathrm{C}\right)$ и скорость подачи раствора (мл/мин). Маркер 30 мкм

Таблица 3. Модель D-оптимального дизайна

\begin{tabular}{|c|c|c|c|c|c|}
\hline \multicolumn{3}{|c|}{ Входящие параметры } & \multicolumn{2}{c|}{ Характеристики конечного продукта } \\
\hline $\begin{array}{c}\text { Концентрация } \\
\left(\mathrm{X}_{1}\right)\end{array}$ & $\begin{array}{c}\text { Температура } \\
\left(\mathrm{X}_{2}\right)\end{array}$ & Скорость $\left(\mathrm{X}_{3}\right)$ & Выход, \% $\left(\mathrm{y}_{1}\right)$ & $\begin{array}{c}\text { Размер, нм } \\
\left(\mathrm{Y}_{2}\right)\end{array}$ & $\begin{array}{c}\text { Дзета- } \\
\text { потенциал, } \\
\text { мВ }\left(\mathrm{Y}_{3}\right)\end{array}$ \\
\hline 1 & 2 & 3 & 5 & 6 \\
\hline 1 & 1 & 1 & 68,3 & 5228 & $-99,3$ \\
\hline 1 & 1 & 0 & 76,3 & 4338 & $-102,0$ \\
\hline 1 & 1 & -1 & 84,0 & 5431 & $-103,0$ \\
\hline 1 & 0 & 1 & 46,3 & 4322 & $-103,0$ \\
\hline 1 & 0 & 0 & 47,3 & 4094 & $-99,8$ \\
\hline 1 & 0 & -1 & 30,6 & 5866 & $-101,0$ \\
\hline 1 & -1 & 1 & 83,0 & 4142 & $-107,0$ \\
\hline 1 & -1 & 0 & 38,2 & 3639 & $-105,0$ \\
\hline 1 & -1 & -1 & 49,0 & 3812 & $-115,0$ \\
\hline 0 & 1 & 1 & 78,7 & 6141 & $-90,8$ \\
\hline 0 & 1 & 0 & 71,0 & 6997 & $-77,4$ \\
\hline
\end{tabular}


Продолжение табл. 3

\begin{tabular}{|c|c|c|c|c|c|}
\hline 1 & 2 & 3 & 4 & 5 & 6 \\
\hline 0 & 1 & -1 & 75,7 & 4201 & $-81,6$ \\
\hline 0 & 0 & 1 & 39,5 & 5149 & $-89,0$ \\
\hline 0 & 0 & 0 & 90,5 & 5674 & $-92,4$ \\
\hline 0 & 0 & -1 & 78,2 & 5677 & $-87,1$ \\
\hline 0 & -1 & 1 & 84,7 & 5561 & $-93,2$ \\
\hline 0 & -1 & 0 & 86,7 & 4866 & $-94,5$ \\
\hline 0 & -1 & -1 & 33,2 & 6513 & $-95,7$ \\
\hline-1 & 1 & 1 & 63,8 & 6983 & $-92,7$ \\
\hline-1 & 1 & 0 & 63,5 & 6063 & $-81,6$ \\
\hline-1 & 1 & -1 & 60,0 & 3710 & $-68,7$ \\
\hline-1 & 0 & 1 & 42,5 & 4846 & $-66,6$ \\
\hline-1 & 0 & 0 & 35,0 & 8604 & $-77,0$ \\
\hline-1 & 0 & -1 & 5,0 & 6416 & $-69,5$ \\
\hline-1 & -1 & 1 & 37,5 & 3129 & $-77,6$ \\
\hline-1 & -1 & 0 & 30,0 & 3161 & $-83,7$ \\
\hline-1 & -1 & -1 & 10,0 & 2072 & $-72,8$ \\
\hline
\end{tabular}
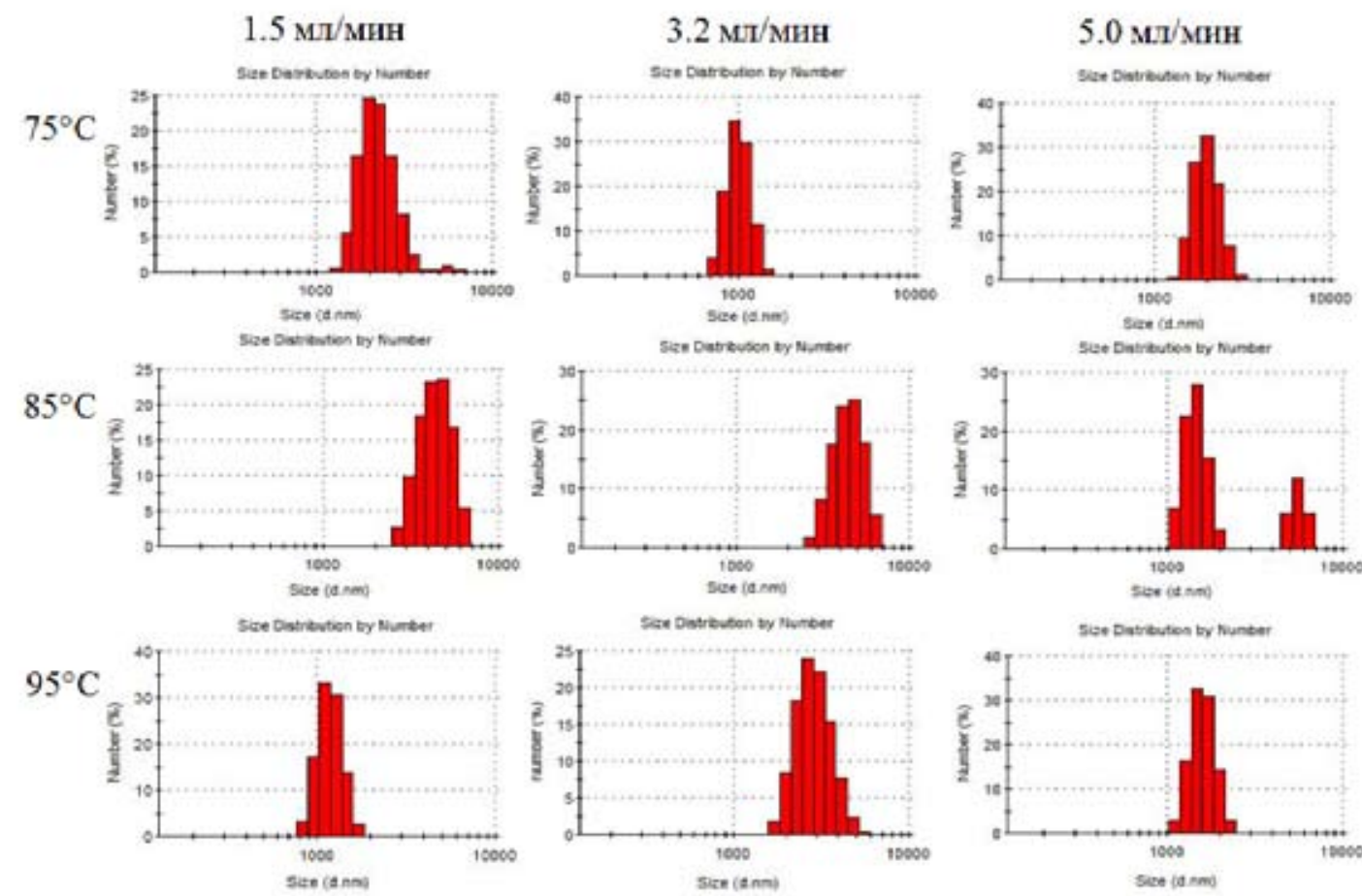

Рис. 7. Размерное распределение полимерных частиц, полученных из 1,5\%-ного раствора П(3ГБ) методом распылительной сушки при варьировании параметров: температура на входе в систему $\left({ }^{\circ} \mathrm{C}\right)$ и скорость подачи раствора (мл/мин) 


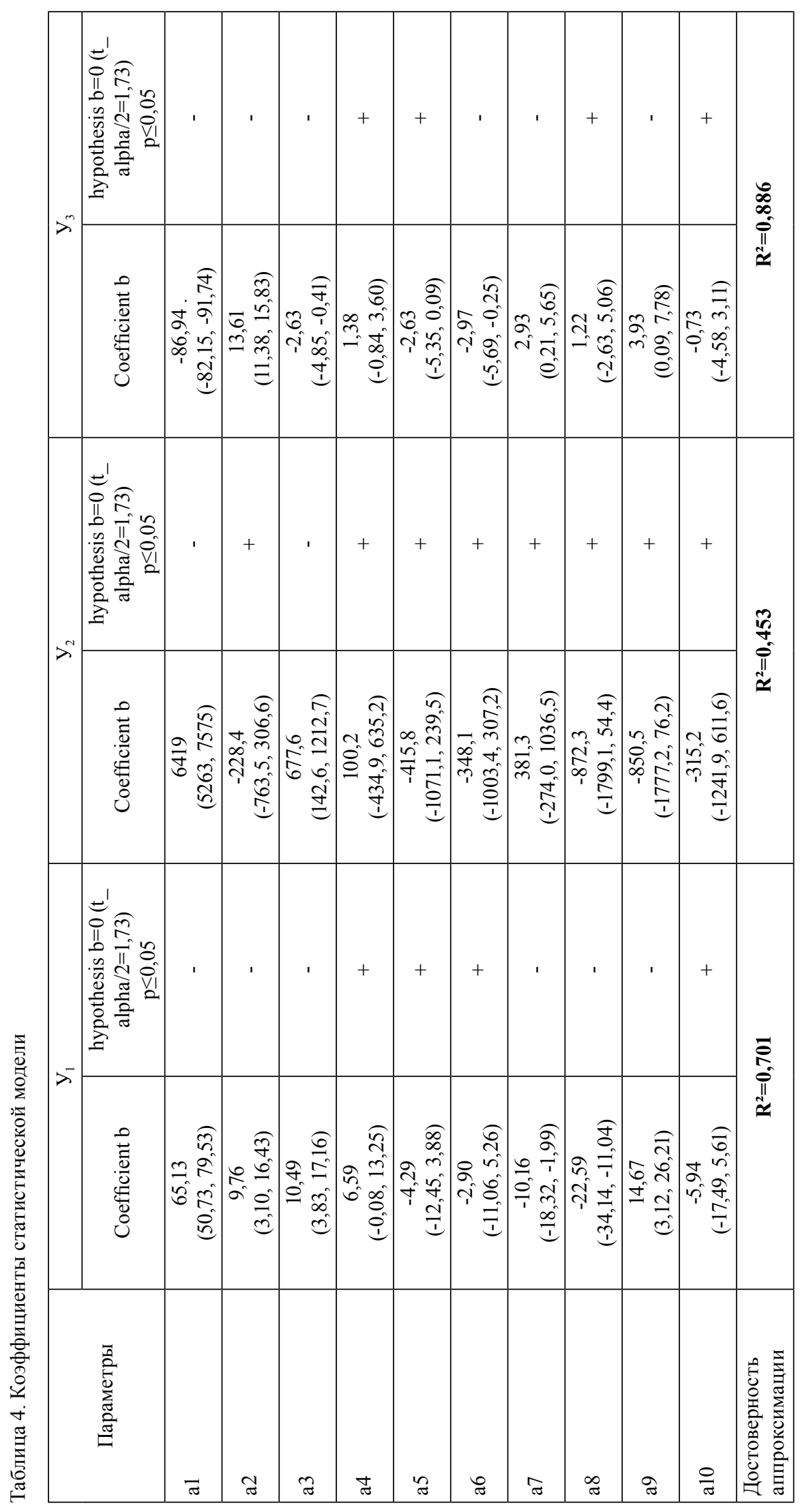


Кроме того, было выявлено влияние нескольких взаимодействий между исследуемыми переменными. Так, величина $\xi$-потенциала в значительной степени зависела от взаимодействия между концентрацией раствора полимера и скоростью подачи раствора, а также скоростью подачи раствора и температурой на входе в систему. Данные оптимизации для выхода микрочастиц показывают $\left(\mathrm{Y}_{1}\right)$, что данный параметр наиболее подвержен влиянию температуры на входе в систему. В этом случае выявлена квадратичная зависимость. При этом, как и на $\xi$-потенциал, на выход микрочастиц оказывали влияние концентрация раствора и взаимодействие между температурой на входе в систему и скоростью подачи раствора.

Результаты исследования достоверности аппроксимации $\left(\mathrm{R}^{2}\right)$ приведены в табл. 4. Из полученных результатов видно, что достоверное влияние всех исследуемых параметров отмечено только на выход и $\xi$-потенциал микрочастиц. В отношении среднего диаметра микрочастиц достоверность аппроксимации низка, а это свиде- тельствует о том, что выбранная модель статистического анализа полностью не описывает зависимость размера полученных микрочастиц от параметров процесса получения.

\section{Заключение}

В работе оптимизированы условия получения микрочастиц из П(ЗГБ) с минимальной потерей продукта. Результаты показали зависимость свойств полученных микрочастиц от параметров процесса. Увеличение скорости подачи раствора и температуры на входе привело к увеличению выхода микрочастиц при низкой концентрации раствора полимера. А увеличение концентрации раствора полимера имело наибольшее влияние на снижение

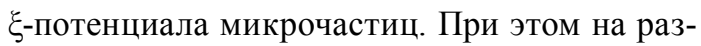
мер микрочастиц достоверно влияло лишь изменение одного параметра - температуры на входе в систему. В целом показано, что применение метода распылительной сушки позволяет упростить технологию получения микрочастиц и полностью её механизировать.

\section{Выражаем благодарность за помощьв в выборе и построении статистической модели} Андрею Николаевцчу Шуваеву, сотруднику Института инженерной физики и радиоэлектроники Сибирского федерального университета.

\section{Список литературы}

1. Волова Т.Г., Гительзон И.И., Калачева Г.С., Кузнецов В.Н., Шабанов В.Ф. Патент РФ № 2207375 «Способ получения полимера $\beta$-оксимасляной кислоты». Заявка №201105608. Приоритет от 27.02.2001. Зарегистрировано в государственном реестре изобретений РФ 27.06.2003.

2. Торговая марка «Биопластотан ${ }^{\mathrm{TM}}$ ». Регистрационное свидетельство № 315652 Федерального института патентной экспертизы по заявке №2006703271/50 приоритет от 15.06.2006. Классы МКТУ: 01, 05, 10. Зарегистрирован в реестре товарных знаков и знаков обслуживания 24.10.2006.

3. Шишацкая Е.И., Горева А.В., Кузьмина А.М. (2012) Исследование лекарственной эффективности доксорубицина. депонированного в микрочастицы из резорбируемого Биопластотана. на лабораторных животных с солидной формой карциномы Эрлиха. Бюллетень экспериментальной биологии и медицины. 154, 12: 741-745.

$$
-207-
$$


4. Anchordoquy T.J., Koe G.S. (2000) Physical stability of nonviral plasmid-based therapeutics. J. Pharm. Sci. 89: 289-296.

5. Bege N., Renette T., Endreset T., Beck-Broichsitter M., Hänggi D., Kissel T. (2013) In situ forming nimodipine depot system based on microparticles for the treatment of posthemorrhagic cerebral vasospasm. Europ. J.Pharm. Biopharm. 84: 99-105.

6. Brandenberger H. (2003) Best@buchi evaporation. Inf Bull, 27p.

7. Daugherty A.L., Mrsny R.J. (2006) Formulation and delivery issues for monoclonal antibody therapeutics. Adv. Drug Deliv. Rev. 58: 686-706.

8. Goreva A.V., Shishatskaya E.I., Volova T.G., Sinskey A.J. (2012) Characterization of polymeric microparticles based on resorbable polyesters of oxyalkanoic acids as a platform for deposition and delivery of drugs. Polym. Sci. Ser. A. 54 (2): 94-105.

9. Jensen D.M., Cun D., Maltesen M.J., Frokjaer S., Nielsen H.M., Foged C. (2010) Spray drying of siRNA-containing PLGA nanoparticles intended for inhalation. J.Control.Release. 142: 138-145.

10. Johnson K.A. (1997) Preparation of peptide and protein powders for inhalation. Adv. Drug Deliv. Rev. 26: 3-15.

11. Kolakovic R., Laaksonen T., Peltonenet L., Laukkanen A., Hirvonen J. (2012) Spray-dried nanofibrillar cellulose microparticles for sustained drug release. Int. J. Pharm. 430: 47-55.

12. Labrude P., Rasolomanana M., Vigneron C., Thirion C., Chaillot B. (1989) Protective effect ofsucrose on spray drying of oxyhemoglobin. J Pharm Sci. 78: 223-229.

13. Lebrun P., Krier F., Mantanuset J., Grohganz H., Yang M., Rozet E., Boulanger B., Evrard B., Rantanen J., Hubert P. (2012) Design space approach in the optimization of the spray-drying process. Europ. J. Pharm. Biopharm. 80: 226-234.

14. Mohajel N., Roholamini Najafabadi A., Azadmanesh K., Vatanara A., Moazeni E., Rahimi A., Gilani K. (2012) Optimization of a spray drying process to prepare dry powder microparticles containing plasmid nanocomplex. Int. J. Pharm. 423: 577-585.

15. Müller R.H.(1996)Zeta potential und Partikelladung-Kurze Theorie, praktische Medurchfuhrung, Dateninterpretation, Wissenschaftliche Verlagsge-sellschaft. Stuttgart, 26 p.

16. Murueva A.V., Shishatskaya E.I., Kuzmina A.M., Volova T.G., Sinskey A.J. (2013) Microparticles prepared from biodegradable polyhydroxyalkanoates as matrix for encapsulation of cytostatic drug. J. Mat. Sci. Mat Med. 24: 1905-1915.

17. Ramezani V., Vatanara A., Najafabadi A.R., Gilani K., Nabi-Meybodi M. (2013) Screening and evaluation of variables in the formation of antibody particles by spray drying. Powder Technology. 233: 341-346.

18. Shoyele S.A., Cawthorne S. (2006) Particle engineering techniques for inhaled biopharmaceuticals. Adv Drug Deliv Rev. 58: 1009-1029.

19. Vehring R. (2008) Pharmaceutical particle engineering via spray drying. Pharmaceutical Research. 25, 5: 999-1022.

20. Wang Y., Kho K., Cheow W.S., Hadinoto K. (2012) A comparison between spray drying and spray freeze drying for dry powder inhaler formulation of drug-loaded lipid-polymer hybrid nanoparticles. Int. J. Pharm. 424: 98-106. 